\title{
Counteracting CAR T cell dysfunction
}

\author{
Mansour Poorebrahim $\mathbb{1}^{1,2} \cdot$ Jeroen Melief ${ }^{1} \cdot$ Yago Pico de Coaña ${ }^{1} \cdot$ Stina L. Wickström ${ }^{1} \cdot$ Angel Cid-Arregui $^{2}$. \\ Rolf Kiessling $\mathbb{1}^{1}$
}

Received: 6 May 2020 / Revised: 22 September 2020 / Accepted: 30 September 2020

(c) The Author(s) 2020. This article is published with open access

\begin{abstract}
In spite of high rates of complete remission following chimeric antigen receptor (CAR) T cell therapy, the efficacy of this approach is limited by generation of dysfunctional CAR T cells in vivo, conceivably induced by immunosuppressive tumor microenvironment (TME) and excessive antigen exposure. Exhaustion and senescence are two critical dysfunctional states that impose a pivotal hurdle for successful CAR T cell therapies. Recently, modified CAR T cells with an "exhaustionresistant" phenotype have shown superior antitumor functions and prolonged lifespan. In addition, several studies have indicated the feasibility of senescence delay in CAR T cells. Here, we review the latest reports regarding blockade of CAR T cell exhaustion and senescence with a particular focus on the exhaustion-inducing pathways. Subsequently, we describe what potential these latest insights offer for boosting the potency of adoptive cell transfer (ACT) therapies involving CAR T cells. Furthermore, we discuss how induction of costimulation, cytokine exposure, and TME modulation can impact on CAR T cell efficacy and persistence, while potential safety issues associated with reinvigorated CAR T cells will also be addressed.
\end{abstract}

\section{Introduction}

In a recent decade, genetically modified immune cells, particularly chimeric antigen receptor (CAR) $\mathrm{T}$ cells, have raised enormous interest in clinical trials [1]. Several generations of CARs have now been developed that are different in the number of intracellular domains or CAR activation mode (Fig. 1). Despite the dramatic clinical benefit of CAR T cell therapy in a broad spectrum of cancer types, a large fraction of patients that achieves remission with CAR $\mathrm{T}$ cell therapy displays disease relapse within a few years [2,3]. Several important explanations of treatment failure in CAR $\mathrm{T}$ cell therapies exist, such as tumor antigen escape and inefficient CAR $T$ cell trafficking into the tumor site. However, it is widely thought that limited CAR $\mathrm{T}$ cell expansion and

Mansour Poorebrahim

mansour.poorebrahim@dkfz-heidelberg.de

Rolf Kiessling

rolf.kiessling@ki.se

1 Department of Oncology-Pathology, Karolinska Institutet, Stockholm, Sweden

2 Targeted Tumor Vaccines Group, Clinical Cooperation Unit Applied Tumor Immunity, German Cancer Research Center (DKFZ), Heidelberg, Germany persistence in the hostile tumor microenvironment (TME) represent additional key impediments to efficacious CAR T cell responses and durable clinical remission following CAR T cell therapy [4]. The observed reduction in proliferative capacities and persistence of CAR T cells is associated with a generalized dysfunctional phenotype that is hallmarked by impaired proliferative and cytotoxic abilities. Importantly, the root cause for development of this dysfunctional state in CAR $\mathrm{T}$ cells is the activation of pathways that promote excessive CAR $T$ cell differentiation, exhaustion, and senescence. Indeed, less-differentiated and less-exhausted CAR T cells have been reported to lead to a better outcome [5]. Central causes for in vivo induction of exhaustion and senescence are persistent stimulation of CAR T cells by high levels of tumor antigens in the face of chronic exposure to a suppressive TME [6]. At the same time, CAR $T$ cell differentiation and exhaustion may be further accelerated by CAR antigenindependent tonic signaling [7].

Given the fact that the efficacy of CAR T cells depends on their capacity to infiltrate the tumor site and directly interact with tumor antigens, in vivo induction of exhaustion and senescence pathways is an unavoidable event in CAR $T$ cell therapies. Indeed, once $T$ cells are activated by the persistent antigen presentation, they subsequently become dysfunctional due to the elevated and sustained expression of inhibitory receptors [8]. Therefore, it is more attractive to focus on approaches to prevent intrinsic 


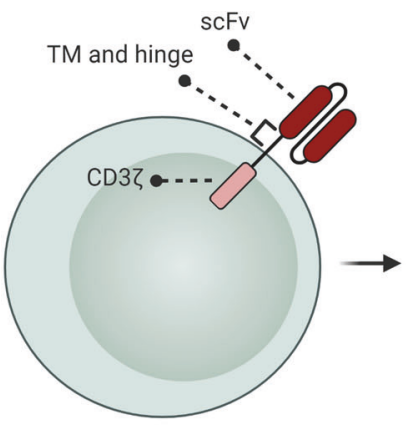

$1^{\text {st }}$ generation

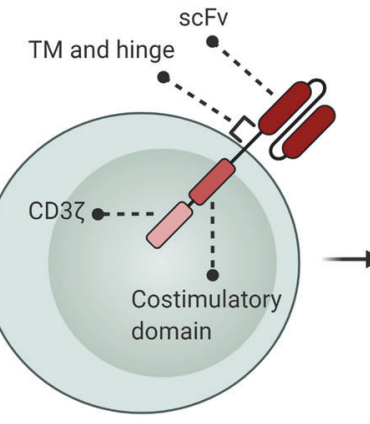

$2^{\text {nd }}$ generation

Fig. 1 Development of CAR generations. CAR structure in CAR $\mathrm{T}$ cells compose of a single-chain variable fragment $(\mathrm{scFv})$, a hinge and transmembrane (TM) region, costimulatory domain(s) (e.g., OX40, CD28, ICOS, 4-1BB), and a CD3 $\zeta$ signaling domain. The 1st generation CARs contained only $\mathrm{CD} 3 \zeta$ as intracellular domain, while

dysfunctional pathways in CAR T cells (e.g., inhibitory receptors signaling) and generate "exhaustion-resistant" cells, rather than aiming to modulate their exposure to tumor antigens in the TME. Through this strategy, the "exhaustion-resistant" CAR T cells might maintain their effector functions even during a prolonged exposure to their cognate antigen. In concordance with this, modified CAR $\mathrm{T}$ cells with disrupted pathways inducing exhaustion or senescence have shown a significantly higher persistence and antitumor activity, providing a promising outlook for reversal or delay of CAR T cell exhaustion and senescence as a way to harness the full potential of this highly effective treatment modality [9-11].

\section{Concept of exhaustion and senescence}

Although exhausted T cells display some phenotypic markers that are typically associated with effector and memory states [12], they show phenotypically and functionally different properties from both effector and memory subsets [13]. Since exhaustion and senescence share several overlapping characteristics such as defective effector functions, impaired proliferation, and cell cycle arrest, they might be used interchangeably. However, there are certain characteristics that can be used to distinguish these states from each other, including cytokine secretion signatures, and expression of cell surface receptors and transcription factors [14].

Recently, Wherry and Kurachi proposed a four-cell-stage model for $\mathrm{T}$ cell exhaustion that is initiated from $\mathrm{TCF} 1^{+}$ exhausted $\mathrm{T}$ progenitors $\left(\mathrm{Tex}^{\mathrm{prog} 1}, \mathrm{Tex}^{\mathrm{prog} 2}\right.$ ), and followed by "intermediate" (Tex ${ }^{\text {int }}$ ) and "terminally" (Tex ${ }^{\text {term }}$ ) exhausted subsets. They found that these cell subset transitions are regulated by the transcription factors TCF1, Tbet, and TOX in a hierarchical developmental pathway [15]. Exhausted $\mathrm{T}$ cells become dysfunctional via a progressive

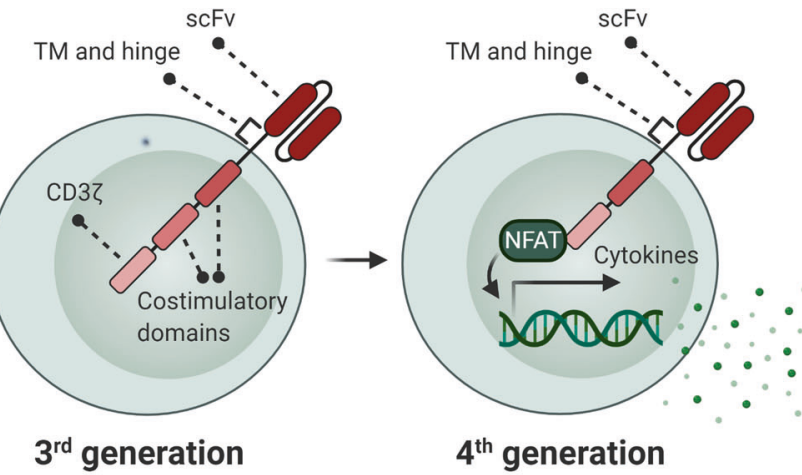

the 2 nd or 3rd generations have one or two costimulatory domains linked to $\mathrm{CD} 3 \zeta$, respectively. The 4 th generation CARs are known as "TRUCK" CARs. These CARs are structurally similar to the 2nd generation CARs, but with an inducible cytokine expression (e.g., IL-12) through NFAT-responsive promoter.
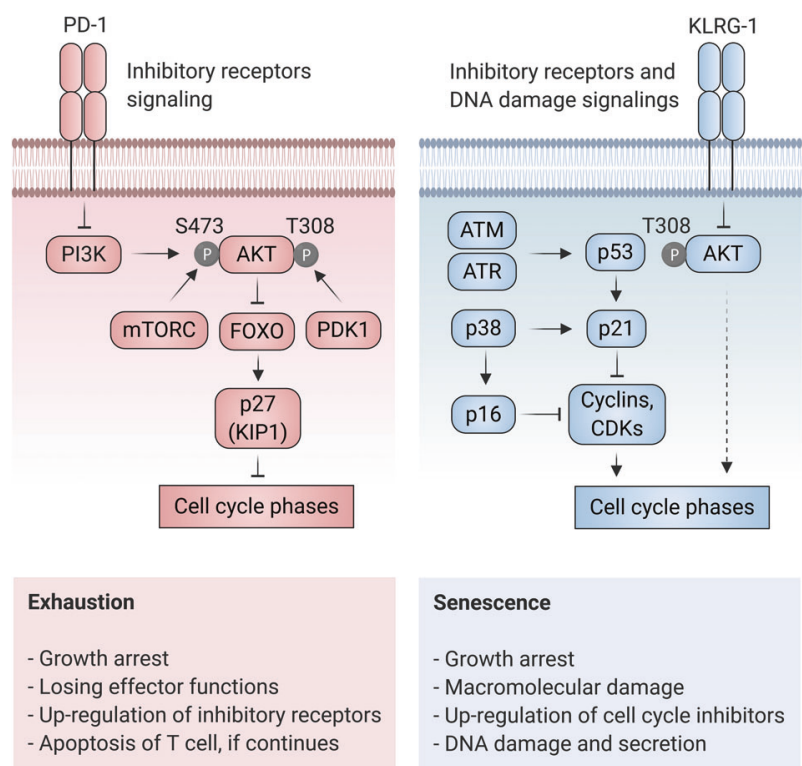

Fig. 2 A scheme for induction of exhaustion and senescence. The principal feature of exhaustion (left) is upregulation of inhibitory receptors such as PD-1. Engagement of PD-1 to its ligand (PD-L1) results in the inhibition of intracellular signaling pathways involved in the regulation of cell proliferation such as PI3K/AKT pathway. Inactivation of AKT (due to the lack of site-specific phosphorylation mediated by PI3K, mTORC (on Serine473), and PDK1 (on Threonine308)) in turn lifts the block on FOXO transcription factors and thereby activates p27, a repressor of cell cycle (G1-S transition). Senescence (right) can be induced by either AKT inhibitory receptors (e.g., KLRG-1) or DNA damage response mediators including ATM and ATR. KLRG-1 prevents AKT phosphorylation (on Serine473) removing its block on $\mathrm{p} 27$, and thereby results in cell cycle arrest. The DNA damage response components activate p53, p21, p38, and p16 which inhibit cell cycle progression by blocking the function of cyclins and cyclin-dependent kinases (CDKs). The figure adapted from [16].

loss of functionality that is mainly mediated by upregulation of multiple inhibitory receptors, including for example PD-1, CTLA-4, TIM-3, which is typically observed in chronic infections and cancers [8, 16] (Fig. 2). However, 
expression of these inhibitory receptors is not an absolute indicator of $\mathrm{T}$ cell exhaustion, as they can also be induced on tumor-specific $\mathrm{T}$ cells upon activation when encountering their cognate tumor antigen [17]. Other major features of $\mathrm{T}$ cell exhaustion include modifications in $\mathrm{T}$ cell receptor (TCR) signaling, cytokine profile, pathways regulating migration, chemokine expression, and metabolic properties [18].

The molecular mechanisms governing induction of cellular senescence are still under investigation. Thus far, several types of senescence have been identified including, (i) replicative senescence or telomere-dependent senescence; (ii) DNA damage-induced senescence; (iii) oncogene-induced senescence; (iv) oxidative stress-induced senescence; (v) chemotherapy-induced senescence; (vi) mitochondrial dysfunction-associated senescence; (vii) epigenetically induced senescence; and (viii) paracrine senescence [19]. Replicative senescence is the most widely characterized senescence type, in which the cells acquire a poor proliferation potential after multiple divisions, and ultimately undergo total growth arrest as a consequence of telomere shortening [20]. In human T cells, the loss of the costimulatory molecules CD27 and CD28, and the high expression of coinhibitory receptors such as KLRG-1, CD57, and TIM-3 are prominent events in the replicative senescence [21]. Of particular interest, KLRG- $1^{+}$or CD57 ${ }^{+}$ $\mathrm{T}$ cells are proliferation incompetent cells with decreased effector cytokine production that are susceptible to apoptosis [22, 23]. Cell cycle arrest through p21 $1^{\text {WAF1/Cip1/ }}$ p16 ${ }^{\mathrm{INK} 4 \mathrm{~A}}$ pathway is a common feature of senescent cells which essentially acts as an alarm in response to damaging stimuli (e.g., DNA damage) or aberrant proliferation [24] (Fig. 2). It was previously thought that, in contrast to a quiescence state, a senescence-associated growth arrest is an irreversible event, but nowadays it is well established that early senescence and exhaustion stages are reversible [16]. Given this finding, blockade of senescence inducing pathways in CAR $\mathrm{T}$ cells may reinstate an enhanced proliferative capacity in a similar manner to blockade or reversal of exhaustion. However, blockade of key mediators of senescence (e.g., p38) in CAR T cells may still cause these cells to have a reduced ability to secrete effector cytokines IFN $\gamma$ and TNF [25].

Collectively, both exhaustion and senescence can be regulated independently, and could be delayed or reversed in CAR $\mathrm{T}$ cells by targeting the specific pathways that govern their induction. In addition, drivers or repressors of exhaustion and senescence might affect various cellular pathways including, immune checkpoint, gene expression, signaling pathways, cell cycle progression, telomere maintenance, and oxidative stress pathways (Table 1). However, exhaustion blockade is assumed to be safer, since senescence acts as a tumor suppressor and efficiently safeguards the cells against damaging stimuli (e.g., DNA damage). Consequently, interventions to alleviate senescence might lead to the development of malignancy [16].

\section{Targeting intrinsic regulators of exhaustion and senescence}

\section{PD-1}

PD-1 is the most common inhibitory receptor expressed on the surface of exhausted CD8 T cells, and its disruption is associated with reversal of $\mathrm{T}$ cell exhaustion as well as increased functionality against tumor cells [26, 27]. Previous data indicated that co-administration of PD-1 blocking antibody could enhance the therapeutic efficacy of CAR T cells [28]. However, this strategy might cause subsequent systemic toxicities. In a safer approach, Brentjens and colleagues coexpressed a PD-1-blocking single-chain variable fragment $(\mathrm{scFv})$ in $\mathrm{CAR} \mathrm{T}$ cells to boost their function and persistence in the TME. The blocking scFv markedly reinvigorated CAR $\mathrm{T}$ cells and restricted its effects mainly to the tumor site, thereby avoiding potential systemic toxicities [9]. In another proof-of-principle study, cytolytic function and cytokine secretion could be restored in exhausted CAR T cells by several approaches disrupting PD-1 interaction with PD-1 ligand (PD-L1), including a PD-1 blocking antibody, PD1 silencing by RNA interference and co-transduction of a PD-1 dominant negative receptor [29]. The feasibility of cotransducing CAR T cells with a PD-1 decoy receptor has been also been proven by other researchers. For example, Huang and colleagues generated a modified B7H3 directed CAR T cell coexpressing a PD-1 decoy receptor consisting of the extracellular PD-1 domain fused to the intracellular stimulatory domain of either CD28 or IL-7 receptor. This decoy CAR was able to convert PD-1 inhibitory signal to costimulatory signals [30]. The advent of CRISPR/Cas9 technology paved the way for additional ways to modify CAR $\mathrm{T}$ cells in the recent years. For instance, CRISPR/Cas9 technology was used by Lim et al. to generate PD-1-deficient anti-CD19 CAR T cells that were highly capable of eradicating tumor cells [31]. However, deletion of PD-1-encoding gene ( $P d c d l)$ may also produce undesirable effects, since Wherry and colleagues reported that it unexpectedly promoted exhaustion and impaired $\mathrm{T}$ cell survival and function [32].

\section{CTLA-4}

Like PD-1, inhibition of the PI3K/AKT pathway is the underlying molecular mechanism by which CTLA-4 induces $\mathrm{T}$ cell exhaustion [8]. A similar scenario can therefore 
Table 1 Genes involved in the regulation of exhaustion and senescence pathways in T cells.

\begin{tabular}{|c|c|c|c|}
\hline Gene name & Pathway & Mechanism of action & Study in CAR T \\
\hline PD-1 & Exhaustion & Immune checkpoint & Yes $[9,28-31,35,114-116]$ \\
\hline CTLA-4 & Exhaustion & Immune checkpoint & Yes $[33,34]$ \\
\hline TIM-3 & Exhaustion/senescence & Immune checkpoint & Yes [37] \\
\hline LAG-3 & Exhaustion/senescence & Immune checkpoint & No \\
\hline CD160 & Exhaustion & Immune checkpoint & No \\
\hline VISTA & Exhaustion & Immune checkpoint & No \\
\hline BTLA & Exhaustion & Immune checkpoint & No \\
\hline KLRG-1 & Senescence & Immune checkpoint & No \\
\hline CD57 & Senescence & Immune checkpoint & No \\
\hline TIGIT & Exhaustion/senescence & Immune checkpoint & Yes [45] \\
\hline 2B4 & Exhaustion & Immune checkpoint & No \\
\hline CD39 & Exhaustion & Immune checkpoint & No \\
\hline CD73 & Exhaustion & Immune checkpoint & No \\
\hline c-JUN & Exhaustion & Gene expression regulation & Yes [11] \\
\hline c-FOS & Exhaustion & Gene expression regulation & Yes [11] \\
\hline JunB & Exhaustion & Gene expression regulation & Yes [11] \\
\hline IRF4 & Exhaustion & Gene expression regulation & No \\
\hline BATF & Exhaustion & Gene expression regulation & Yes [11] \\
\hline BATF3 & Exhaustion & Gene expression regulation & Yes [11] \\
\hline NFAT & Exhaustion & Gene expression regulation & No \\
\hline Eomes & Exhaustion & Gene expression regulation & Yes [51] \\
\hline T-bet & Exhaustion & Gene expression regulation & Yes $[50]$ \\
\hline TOX & Exhaustion & Gene expression regulation & Yes [55] \\
\hline NR4A & Exhaustion & Gene expression regulation & Yes $[10]$ \\
\hline BLIMP1 & Exhaustion & Gene expression regulation & No \\
\hline TCF1 & Exhaustion & Gene expression regulation & Yes [104] \\
\hline DNMT3A & Exhaustion & Gene expression regulation & No \\
\hline PI3K & Exhaustion/senescence & Signaling mediator & Yes $[58,61]$ \\
\hline AKT & Exhaustion/senescence & Signaling mediator & Yes [57] \\
\hline mTOR & Exhaustion/senescence & Signaling mediator, cell cycle regulation & Yes [5] \\
\hline FOXO & Exhaustion/senescence & Signaling mediator, cell cycle regulation & Yes [50] \\
\hline PTPN2 & Exhaustion & Signaling mediator & Yes [68] \\
\hline PP2A & Exhaustion & Signaling mediator & Yes [69] \\
\hline LCK & Exhaustion & Signaling mediator & Yes [70] \\
\hline SHP1/SHP2 & Exhaustion & Signaling mediator & Yes [70] \\
\hline $\mathrm{A} 2 \mathrm{AR}$ & Exhaustion & Signaling mediator & Yes $[76,78]$ \\
\hline PKA & Exhaustion & Signaling mediator & Yes [79] \\
\hline TGFBR1/TGFBR2 & Exhaustion & Signaling mediator & Yes [82-84] \\
\hline PDK1 & Exhaustion & Signaling mediator & No \\
\hline PKC & Exhaustion & Signaling mediator & No \\
\hline p38 & Senescence & Signaling mediator & No \\
\hline PIR-B & Exhaustion & Signaling mediator & No \\
\hline $\mathrm{p} 21^{\mathrm{CIP} 1}$ & Senescence & Cell cycle regulation & No \\
\hline $\mathrm{p} 16^{\mathrm{INK} 4 \mathrm{~A}}$ & Senescence & Cell cycle regulation & No \\
\hline p53 & Senescence & Cell cycle regulation & No \\
\hline $\mathrm{RB}$ & Senescence & Cell cycle regulation & No \\
\hline hTERT & Senescence & Telomeres stabilization & Yes [87] \\
\hline CAT & Exhaustion/senescence & Oxidative stress response & Yes [90] \\
\hline
\end{tabular}


be considered to reverse the dysfunctional state of CAR T cells induced by CTLA-4 pathway. Simultaneous blockade of CTLA-4, PD-1, and TIM-3 in CAR T cells by socalled blocking minibodies enhanced their effector functions. Among the different combinations of minibodysecreting CAR $\mathrm{T}$ cells, however, only the anti-CTLA-4 minibody-secreting CAR $\mathrm{T}$ cells showed prolonged function, signifying the unique characteristics of this immune checkpoint mediator [33]. Using a similar concept, checkpoint-resistant CAR T cells with genetic ablation for TCR, HLA class I, PD-1, and CTLA-4 were generated by a one-shot CRISPR system. However, the disruption efficiency minimized with increased numbers of target genes, which might be due to competition between multiple guide RNAs (gRNAs) for Cas9. In addition, the in vivo efficacy and lifespan of these PD-1- and CTLA-4-deficient CAR $\mathrm{T}$ cells need to be further examined [34].

\section{TIM-3 and LAG-3}

Blockade of PD-1 in combination with other immune checkpoint receptors, including TIM-3 and LAG-3, has strong synergistic effects, and boosts effector functions of CAR T cells [35, 36]. The high efficacy of this combinatorial approach suggests that TIM-3 and LAG-3 pathways have non-redundant effects that synergize with PD-1 signaling to dampen antitumor responses in dysfunctional CAR $\mathrm{T}$ cells. As that the precise mechanisms by which TIM-3 and LAG-3 induce T cell exhaustion and senescence are still not fully understood, only a few studies have explored selective blockade of these inhibitory receptors in CAR T cells. In one effort, antibody-based blocking of Galectin-9, a putative TIM-3 ligand, reduced exhaustion of CAR T cells and significantly increased their cytotoxicity against previously resistant tumor cells [37]. Of note, FGL1 has been identified as a major ligand for LAG-3, and possibly will be considered as a candidate target for LAG-3 signaling blockade in the future studies [38]. Additionally, it has been speculated that intracellular trafficking and cell surface expression of LAG-3 is dependent on PKC signaling, revealing a role of $\mathrm{PKC}$ in mediating $\mathrm{T}$ cell exhaustion [39]. This notion is in contrast with the recent finding that exhaustion is reversed in $\mathrm{T}$ cells by $\mathrm{PKC}$-inducing small molecules [40]. An explanation for this discrepancy is that the function of PKC- $\theta$ can be disrupted by PD-1/SHP-2dependent CD28 inactivation, as CD28 is necessary for PKC- $\theta$-mediated downstream signaling [41, 42]. Therefore, augmentation of PKC functioning might be useful for bypassing the suppressive PD-1 signaling. However, the distinct role of $\mathrm{PKC}$, especially regarding different $\mathrm{PKC}$ isoforms, in $\mathrm{T}$ cell exhaustion seems to remain controversial.
TIGIT

TIGIT is a recently identified immune checkpoint that is transiently overexpressed in activated dysfunctional CD8 $\mathrm{T}$ cells, regulatory $\mathrm{T}$ cells, and natural killer (NK) cells that mediates signaling for exhaustion and senescence in host cells upon binding to its ligands (CD155 and CD112) on the surface of antigen-presenting cells (APCs) [36, 43, 44]. Similar to TIM-3 and LAG-3, the knowledge about the intracellular signaling cascade activated by TIGIT during induction of exhaustion and senescence is largely incomplete. Since TIGIT competes with its costimulatory counterpart, CD226 (DNAM-1), for binding to the same ligands, engagement of TIGIT with its ligands diminishes costimulation signaling in the host cells. In line with this, concomitant expression of a TIGIT-based chimeric costimulatory switch receptor composing of the extracellular domain of TIGIT and the signaling domain of CD28, called TIGIT-28, endowed a superior antitumor function to the anti-CD19 CAR T cells, while rescuing the hypofunctional $\mathrm{T}$ cells [45].

\section{C-JUN/C-FOS axis}

Dysregulation of AP1 transcription factor-binding motifs is a predominant epigenetic alteration in exhausted $\mathrm{T}$ cells, which leads to increased expression of exhaustion-related transcription factors from bZIP/IRF family (BATF3, IRF4) and/or AP1 family (BATF, JunB). These events subsequently elicit inhibitory signaling molecules in T cells, such as PD-1 [11, 46]. In a recent work, Mackall and colleagues overexpressed c-JUN, an AP1 family transcription factor involved in $\mathrm{T}$ cell activation, in CAR $\mathrm{T}$ cells to reverse the dysfunctional state of exhaustion-prone CAR T cells. They showed that CAR $\mathrm{T}$ cells with forced overexpression of $\mathrm{c}$ JUN became exhaustion-resistant and displayed enhanced functional capacities as well as a reduced expression of exhaustion markers PD-1 and CD39. Mechanistically, cJUN prevented development of terminally exhausted CAR T cells by directly activating AP1 complex (c-JUN/c-FOS), and indirectly disrupting AP1i complex (exhaustion-associated complex) through displacing JunB, BATF, and BATF3 from chromatin [11]. Another possible interpretation is that c-JUN competes for chromatin binding with NR4A family members, which regulate $\mathrm{T}$ cell exhaustion, as c-JUN and NR4A1 share a substantial number of common chromatin-binding sites [47]. Intriguingly, although cJUN overexpression increased expansion of CAR T cells, it had no marked effect on cytokine production. Moreover, future studies are warranted to fully understand why overexpression of c-FOS alone, unlike c-JUN, did not lead to the enhanced functioning of CAR T cells [11]. 


\section{Eomes and T-bet}

The transcription factors Eomes and T-bet play a key role in differentiation and exhaustion of T cells. Eomes knockdown restores the functional defects of exhausted $\mathrm{T}$ cells, indicating its positive impact on the development of $\mathrm{T}$ cell exhaustion. Conversely, T-bet ${ }^{\text {hi }} \mathrm{T}$ cells express an intermediate level of inhibitory receptors, and are linked to the high functional properties [48, 49]. However, new data suggest that T-bet, in a key interplay between TCF1 and TOX, has a role in the development and dynamics of $\mathrm{T}$ cell exhaustion [15]. In the absence of IL-12, CAR T cells secreting IL-18 switched to a T-bet ${ }^{\text {hi }}$ FOXO1 ${ }^{\text {lo }}$ phenotype that prevented exhaustion and augmented antitumor immunity [50]. In a case study, PD-1 blockade increased CAR T cell efficacy and expansion, and decreased Eomes expression, implying a positive correlation between PD-1 and Eomes expression in terminally exhausted CAR T cells [51].

\section{TOX/NR4A axis}

The sustained expression of TOX, an HMG-box transcription factor involved in the regulation of thymocyte selection [52], in exhausted $\mathrm{T}$ cells is associated with impaired antitumor activity, and its downregulation alleviates $\mathrm{T}$ cell exhaustion $[15,53]$. This transcription factor is induced by calcineurin and NFAT, and is implicated in the early epigenetic events responsible for fate commitment of exhausted $\mathrm{T}$ cells [54]. In addition to TOX, calcineurin-regulated NFAT can regulate the expression of NR4A, which cooperates with TOX proteins in a positive feedback loop to induce exhaustion in PD- ${ }^{\text {hi }}$ TIM- $3^{\text {hi }}$ CAR T cells [55]. Therefore, disruption of TOX and NR4A function may inhibit the induction of exhaustion in CAR T cells. In line with this, TOX- and NR4A-deficient CAR T cells demonstrated increased cytokine production and decreased expression of inhibitory receptors [55]. Moreover, NR4A triple knockout CAR T cells lacking NR4A1, NR4A2, and NR4A3 with a PD- $1^{\text {hi }}$ TIM- $3^{\text {hi }}$ phenotype exhibited a superior effector phenotype. Of note, chromatin accessible regions in these modified CAR $\mathrm{T}$ cells were selectively enriched for binding motifs for $\mathrm{NFkB}$ and $\mathrm{AP1}$, which are actively involved in regulation of $\mathrm{T}$ cell effector functions [10].

\section{PI3K/AKT/mTOR/FOXO axis}

In human lymphocytes, the PI3K-AKT pathway plays a critical role in regulating $\mathrm{T}$ cell differentiation and activity. Although this signaling pathway is essential for TCR signaling and production of cytolytic molecules [14], constitutively active AKT induces terminal differentiation and formation of KLRG- ${ }^{+}$effector T cells [56]. The advantage of AKT targeting is that there are numerous available AKT inhibitors compatible with CAR T cell expansion ex vivo. For instance, expansion of CAR T cells in the continuous presence of an allosteric kinase inhibitor (AKT Inhibitor VIII; AKTi) could generate minimally differentiated CD62L-expressing memory cells with superior antitumor function, without compromising cell yield [57].

It has been postulated that PI3K-mediated CAR T cell exhaustion is occurred through its role in tonic CAR signaling during ex vivo expansion, and this is why PI $3 \mathrm{~K}$ inhibitors preserve less-differentiated state of CAR T cells with heightened in vivo persistence [58]. PI3Ks are composed of four validated isoforms including, $\mathrm{PI} 3 \mathrm{~K} \alpha, \mathrm{PI} 3 \mathrm{~K} \beta, \mathrm{PI} 3 \mathrm{~K} \gamma$, and PI3K $\delta$, but only inhibition of PI3K $\delta$ has resulted in a delay in terminal differentiation of $\mathrm{T}$ cells [59]. Consistent with this, mutation-derived hyperactive PI3K $\delta$ decreased the threshold of exhaustion and senescence in $\mathrm{T}$ cells through cumulative epigenetic aberrations in the promoter region of inhibitory receptors (e.g., demethylation of the PD-1 promotor), leading to an increase in the inhibitory signaling [60]. This inhibitory effect was reported to be diminished in CAR T cells when PI3K $\delta$ was selectively blocked by Idelalisib (CAL-101). The blockade switched CAR T cells to an undifferentiated phenotype $\left(\mathrm{CD} 2 \mathrm{~L}^{+} \mathrm{CAR} \mathrm{T}\right)$ that expressed lower levels of exhaustion markers [61].

The transcription factor mTOR is a multifunctional regulator of $\mathrm{T}$ cell metabolism that plays various roles in the regulation of exhaustion and senescence pathways. On the one hand, activation of mTOR, when accompanied by cell cycle arrest and DNA damage, promotes cell senescence $[62,63]$. On the other hand, mTOR activation leads to a decreased cell exhaustion via declined FOXO function [16], a critical rheostat downstream of mTOR that sustains PD-1 signaling to promote the exhaustion of PD- $1^{\text {hi }}$ Eomes ${ }^{\text {hi }}$ $\mathrm{T}$ cells [64]. Moreover, FOXO differentially regulates T-bet and Eomes, two transcription factors implicated in type I effector and differentiated memory phenotypes, respectively [65]. These findings support the notion that regulation of FOXO by PD-1 is necessary for induction of $\mathrm{T}$ cell exhaustion [16], and importantly, the whole process is augmented by a positive feedback loop between PD-1 and FOXO [64]. However, FOXO-deficient $\mathrm{T}$ cells fail to retain their persistence, indicating the functionally diverse mechanisms of this transcription factor in the regulation of $\mathrm{T}$ cell exhaustion and longevity [64, 65]. Thus, the impact of mTOR/FOXO axis on the T cell exhaustion/senescence is likely determined under specific circumstances. Preferably, targeting of mTOR/FOXO axis in the CAR T cells is performed by cytokine exposure. Ex vivo expansion of CAR T cells in the presence of IL-15 (or IL-2 with mTOR inhibitors) resulted in a less-exhausted stem cell memory $\mathrm{T}$ $\left(\mathrm{T}_{\mathrm{scm}}\right)$ phenotype with higher anti-apoptotic properties, and enhanced the proliferative capacity of CAR T cells. The authors argued that depletion of mTORC1 activity was a 
hallmark of the IL15-mediated harnessing of CAR T cell dysfunction [5]. In another platform, a FOXO1 ${ }^{\text {lo }}$ T-bet $^{\text {hi }}$ phenotype was induced in CAR T cells via inducible IL-18 expression, and the modified CAR $\mathrm{T}$ cells had superior antitumor function and prolonged survival [50].

\section{PTPN2 and PP2A}

It has been recently established that the phosphatases PTPN2 and PP2A act as a critical regulator of CD8 + T cell exhaustion by attenuating the type 1 interferon pathway and mediating CTLA-4 signaling, respectively [66, 67]. Recently, stronger activation and improved tumor infiltration was observed in PTPN2-deficient CAR T cells, which were less prone to exhaustion. The authors concluded that this "exhaustion-resistant" phenotype of CAR T cells was obtained by upregulation of LCK and cytokine-induced STAT-5 signaling [68]. However, suppressing CAR T cell exhaustion by PTPN2 ablation might not always have desirable output, as for example deletion of the PTPN2encoding gene (Ptpn2) in CD8 T cells enhanced the ratio of terminally exhausted $\mathrm{T}$ cell populations (TIM- ${ }^{+} \mathrm{T}$ cells) to progenitor exhausted $\mathrm{T}$ cells (SLAMF6 $^{+} \mathrm{T}$ cells) by increasing the number of TIM- $3^{+}$cells without depleting the pool of SLAMF6 ${ }^{+}$populations [66]. To disrupt PP2A function, Zhuang and colleagues used the small molecule LB-100, and found that inhibition of this phosphatase increased the therapeutic efficacy of CAR T cells [69].

\section{LCK and SHP1/SHP2}

SHP1 counteracts the effect of LCK and dephosphorylates key components of TCRs and CARs including $\mathrm{CD} 3 \zeta$, specifically in $\mathrm{BB} \zeta$ CARs [70]. Although dispensable, SHP2 is also considered as a molecule involved in development of $\mathrm{T}$ cell exhaustion [71]. These phosphatases are recruited to the cytoplasmic portion of PD-1 and other inhibitory receptors, and negatively regulate IL-2 production upon PD-1 engagement [72]. Some preliminary data are available that report the feasibility of SHP1 ablation in CAR T cells [73, 74]. In a recent report, Dotti et al. engineered LCK and SHP1 to be recruited within the synapse of $\mathrm{T}$ cells expressing $\mathrm{BB} \zeta$ and $28 \zeta$ CARs, respectively. The results indicated that overexpression of LCK in CAR T cells encoding 4-1BB could boost the expansion capacity and antitumor functions. Remarkably, LCK-mediated CAR T cell activation did not show any increase in expression of inhibitory receptors. In contrary, recruitment of SHP1 to the synapse of CD28-encoding CAR T cells by heterodimerization of the small molecule AP21967 did not augment antitumor effects, but decreased the severity of cytokine release syndrome (CRS) [70]. These findings highlight the potential of LCK and SHP1 for generating
CAR T cells with predictable activity and toxicity profiles, respectively.

\section{A2AR/PKA axis}

In the hypoxic conditions, the HIF-1 $\alpha$ pathway is amplified in tumor cells, which leads to upregulation of CD73 and CD39, two ectonucleotidases involved in adenosine signaling on the surface of both tumor and $\mathrm{T}$ cells [75]. Adenosine is known as an immunosuppressive molecule that exerts an inhibitory signal within $\mathrm{T}$ cells following its A2AR-mediated delivery into cytoplasm and subsequent conversion to the cyclic AMP (cAMP). In the TME, CAR $\mathrm{T}$ cells upregulate A2AR that predominantly suppresses endogenous antitumor responses via facilitating the adenosine-to-cAMP conversion [76]. Inhibition of A2AR results in greater expansion of tumor-specific CD8 T cells [77], which suggests that this receptor may represent a highly translational target for blocking $\mathrm{T}$ cell exhaustion. As shown independently by two groups, pharmacological targeting of A2AR or expression of an anti-A2AR short hairpin RNA (shRNA) in CAR T cells restored their proliferation and cytokine production deficits caused by the adenosine signaling [76, 78]. In association with Ezrin, PKA sustains the inhibitory effect of adenosine signaling by blocking TCR signaling in CAR T cells. Previous data showed that expression of a peptide-based inhibitor of PKA and blocking of Ezrin association blunted the negative effect of adenosine/PKA/Ezrin axis in CAR T cells [79].

\section{TGFBR1/TGFBR2}

TGF- $\beta$ secretion in TME is particularly evident in resistant tumors, and is associated with poor antitumor immunity and clinical outcome [80]. Of particular interest here, activation of TGF- $\beta$ signaling in tumor-reactive T cell acts as a potent inducer of exhaustion pathways via phosphorylation of SMAD2 and SMAD3 ahead of immune checkpoints. This reflects a hierarchy of inhibitory events during $T$ cell exhaustion that is initiated by TGF- $\beta$ signaling cascade and that subsequently progresses due to PD-1/PD-L1 interaction [81, 82]. To address this, various immunotherapies based on blocking TGF- $\beta$ (signaling) are in clinical development, which holds promise for revitalizing $\mathrm{T}$ cell antitumor activity in resistant tumors [81]. In CAR $\mathrm{T}$ cell therapy, these approaches have focused on targeting TGF- $\beta$ receptors. For example, Wang et al. knocked out the endogenous TGFBR2 in CAR T cells with CRISPR/Cas9 technology to prevent exhaustion by blocking TGF- $\beta$-induced phosphorylation of SMAD proteins. Impressively, knocking out TGFBR2 bestowed CAR T cells with superior proliferative and tumoricidal capabilities, both in vitro and in vivo [82]. In another attempt, a dominant-negative TGFBR2 was 
coexpressed in PSMA-specific CAR T cells. The engineered CAR T cells were resistant to exhaustion, while they displayed enhanced abilities to proliferate and secrete cytokines. However, the enhanced proliferation of CAR $\mathrm{T}$ cells was associated with lymphoproliferative syndrome, emphasizing the safety considerations to be addressed before employing this approach [83]. A successful TGF- $\beta$ signal conversion platform has also been reported in recent years. In this approach, $T$ cells were transduced with chimeric variants of TGFBR1 and TGFBR2 containing the TGF- $\beta$-binding domain of each receptor and the intracellular signaling domains of a $\mathrm{T}$ cell stimulating interleukin receptor. As anticipated, TGF- $\beta$ exposure induced STAT signaling (instead of SMAD2/3 signaling), and promoted effector function and persistence of CAR T cells [84].

\section{hTERT}

Endogenous hTERT, which encodes the catalytic component of the telomerase complex, serves as a major determinant of human $\mathrm{T}$ cell longevity. Expression of this gene is decreased in the memory $\mathrm{T}$ cells upon antigen encounter [85]. It has been indicated that hTERT downregulation directly imposes replicative senescence in terminally differentiated T cells [20]. Having observed these findings, ectopic hTERT expression in $\mathrm{T}$ cells restored gradual loss of telomeric DNA, and extended the lifespan of $\mathrm{T}$ cells without loss of functionality [86]. As yet, limited data has been obtained in the CAR T cells. In an attempt, Bai et al. could successfully increase the proliferative capacity of CD19-directed CAR T cells using a transiently coexpression of hTERT. The hTERT upregulation improved antitumor effects of CAR T cells, and delayed initiation of replicative senescence [87].

\section{CAT}

Although low concentrations of reactive oxygen species (ROS), most notably $\mathrm{H}_{2} \mathrm{O}_{2}$, act as signal molecules and trigger intracellular signaling as well as defense pathways against pathogens, increased levels induce cell senescence and exhaustion pathways [88]. Effector T cells encountering the hostile TME or viral infections are skewed toward state with reduced effector functioning, reduced glucose uptake and glycolysis, upregulated inhibitory receptors, and increased ROS levels [89]. This gives rise to the rationale that blockade of high-level ROS can reinvigorate CAR $\mathrm{T}$ cells in vivo. Indeed, CAR $\mathrm{T}$ cells coexpressing CAT enzyme, an antioxidant enzyme that specifically scavenges $\mathrm{H}_{2} \mathrm{O}_{2}$, were largely protected against intrinsic and extrinsic oxidative stress, and demonstrated higher persistence and efficacy [90]. Even though increased ROS levels in the TME are generally unfavorable for CAR T cell function, it has been shown that pre-treatment of cancer cells with a ROS accelerator renders them more susceptible to CAR T cell-mediated killing. These ROS accelerators did not affect CAR T cell function, opening a window of opportunity for combinational treatment using armored CAR $\mathrm{T}$ cells and ROS accelerators [91].

Overall, prevention of CAR T cell dysfunction through blockade of major drivers of exhaustion and senescence, or by augmentation of repressors of exhaustion and senescence has led to some appealing results that could potentially contribute to improved CAR T cell-based immunotherapies. The considerable number of genes targeted for this purpose in CAR T cells, either by genetic modification or pharmacological interventions, are depicted in Fig. 3.

\section{Costimulation induction and cytokine exposure}

After priming of $\mathrm{T}$ cells by antigens, costimulatory factors, and inflammation mediators, they can subsequently differentiate into two new subsets: (i) highly polyfunctional memory $\mathrm{T}$ cells, enabling them to become vigorously cytolytic with high proliferative potential; (ii) dysfunctional $\mathrm{T}$ cells with almost no effector functions, which show a progressive increase in the number, diversity, and "intensity" of inhibitory receptors [13] (Fig. 4). Therefore, differentiation of functional CAR T cells into exhausted or senescent stage is a predictable phenomenon in the tumors with suppressive barriers and high antigen load. But a question emerges: whether the costimulation induction and cytokine exposure can prevent or delay the onset of exhaustion or senescence of CAR T cells? To address this, several studies have demonstrated an enhanced persistence and efficacy in the CAR $\mathrm{T}$ cells when exposed to the costimulatory molecules or cytokines [7, 92-94].

CD28 and 4-1BB intracellular domains are the most widely used domains for generation of CARs, which are associated with prompt effector response and long-term function, respectively [95]. New costimulatory factors have also shown to have a role in the persistence of CAR T cells. As suggested by June et al., incorporation of ICOS (also called CD278) and 4-1BB intracellular domains into CARs remarkably augmented the effector function and persistence of CAR T cells. Interestingly, the strong costimulatory effect was observed only when ICOS domain was linked to its transmembrane peptide, and thereby positioned proximal to the cell membrane [92]. This demonstrates that proper selection and configuration of costimulatory domains is an essential consideration. In functional terms, ICOSbearing CARs were initially identified to preserve the signature characteristics of CD4 $\mathrm{T}_{\mathrm{H}} 17$ cells. This costimulatory domain could induce antitumor responses (by upregulating 


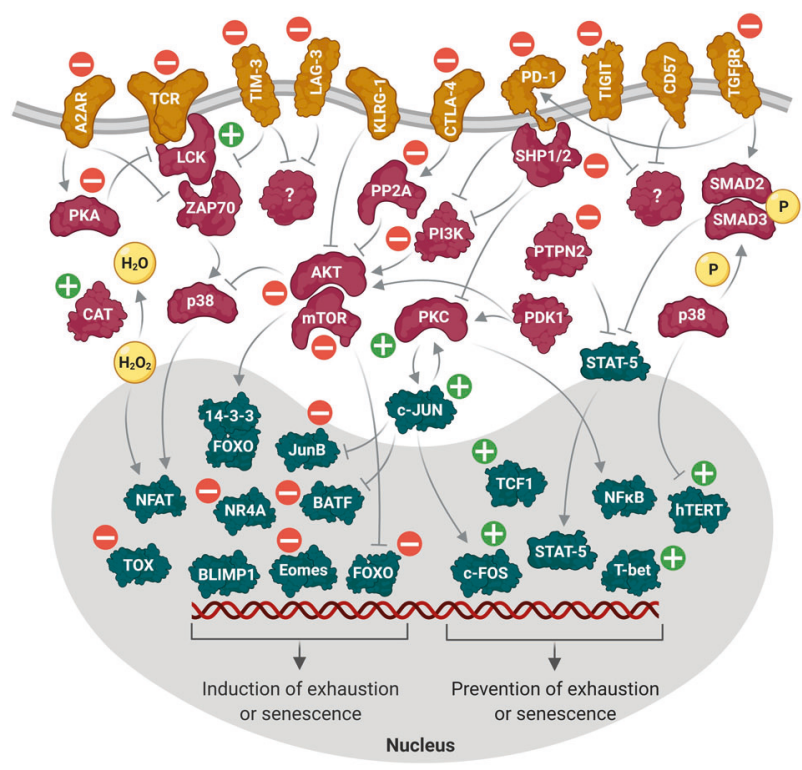

Fig. 3 Intracellular network between exhaustion or senescence regulators. Competition between exhaustion or senescence regulators and inhibitors determines the fate of CAR T cell in the TME. Inhibitory receptors transfer exhaustion/senescence signal to the inhibitory transcription factors (i.e., FOXO, Eomes, BATF, BLIMP1, TOX, NR4A, IRF4, NFAT, etc.) via downstream signaling pathways, whereas exhaustion/senescence delaying transcription factors (i.e., c-FOS, TCF1, T-bet, NFkB, etc.) counteract these inhibitory signals. The green plus and red minus signs refer to the enhanced/upregulated and blocked/downregulated genes in CAR T cells, respectively.

IFN $\gamma$ ) and mitigate exhaustion (by upregulating T-bet) in $\mathrm{T}_{\mathrm{H}} 17$ cells carrying a CAR [96]. This finding led to the extension of ICOS-based CARs to the CD8 T cells [92].

Previous studies suggest that antigen-independent tonic signaling by CARs, perhaps due to the physical interactions between CARs or $\mathrm{scFv}$ dimerization, limits CAR $\mathrm{T}$ cells potency by induction of exhaustion pathways. This antigenindependent exhaustion can be tolerated by CAR $T$ cells through tonic 4-1BB signaling. [97]. However, other parts of the CAR construct design as well as the transduction method used to generate CAR T cells can also contribute to the extent of tonic signaling, and the effect of CD28/4-1BB domains should be evaluated for each individual CAR [7, 97]. Recruitment of TRAF proteins and induction of noncanonical NFKB signaling are critical events in 4-1BB costimulation, and contribute to mitigated exhaustion [98, 99]. Importantly, endodomains of CD28 may promote antigen-independent exhaustion, since replacing of this costimulatory molecule with 4-1BB reversed exhaustion in CAR T cells [7]. Recently, Posey et al. reported that a single asparagine (Asn) amino acid in the intracellular domain of CD28 is responsible for CD28-mediated exhaustion in CAR T cells. Substituting this Asn to phenylalanine hindered cell exhaustion and led to a durable antitumor response [100].

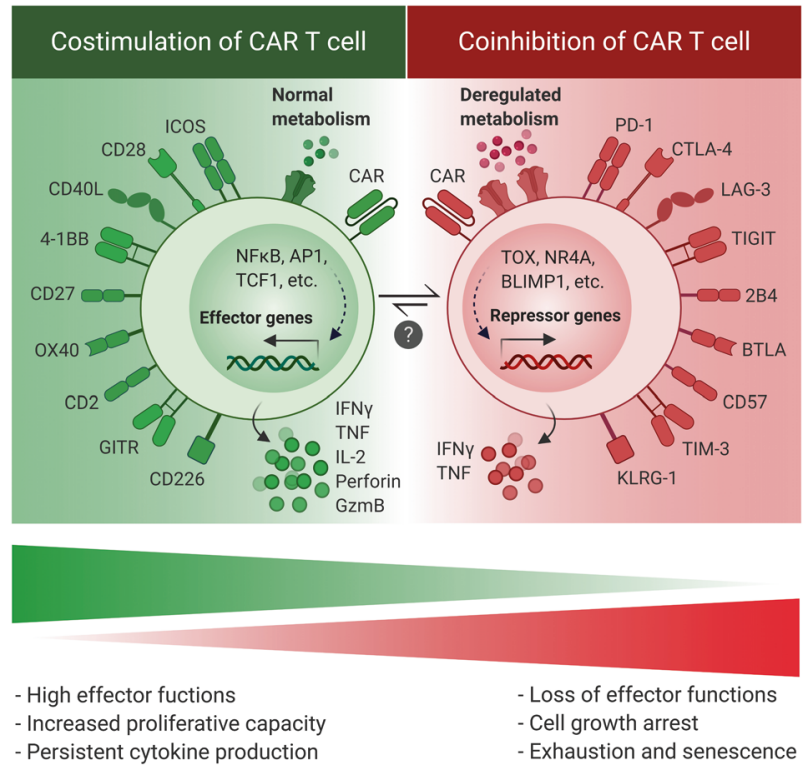

Fig. 4 Costimulation and coinhibition of CAR T cell. Upregulation of costimulatory and coinhibitory receptors on the surface of CAR $\mathrm{T}$ cells is associated with effector polyfunctional and exhausted hypofunctional phenotypes, respectively. The final functional outcome depends on the number and diversity of relevant receptors. Although differentiation of functional CAR T cells to the exhausted/senescent phenotype is a common phenomenon in the tumor site, the possibility of reinvigorating exhausted/senescent CAR T cells is still a question.

Based on these findings, although induction of CD28 signaling will apparently restore the immunocompetence of senescent CAR T cells [101], it might drive the cells into states of exhaustion and dysfunction. Therefore, the mutant-type CD28 (with substituted Asn in the YMNM motif) costimulation in CAR T cells may result in more benefits [100].

Cytokines are able to provide further stimulatory signals for $\mathrm{T}$ cell activation, and therefore have been effectively used to exert a spectrum of pleiotropic effects on CAR T cell proliferation and function [102]. Apparently, the rationale underlying this approach's efficiency is that cytokines are able not only to convert the inherent features of hypofunctional CAR $\mathrm{T}$ cells to the effector signature, but also to reduce the number of suppressor cells in TME, resulting in an augmented immunity [50, 93, 94, 101, 103]. Apart from IL-2, the most widely used cytokine to culture CAR T cells for ACT, a number of other cytokines such as IL-7, IL-15, IL-18, and IL-21 have shown promising outputs [93, 94, 102, 103]. In a clinical setting, Dotti et al. demonstrated that IL-7 and IL-15 preserved more CAR $\mathrm{T}$ cells with $\mathrm{T}_{\mathrm{scm}}$ phenotype. High frequency of these lessdifferentiated CAR $\mathrm{T}$ cells was correlated with overall in vivo expansion and persistence in lymphoma patients [93]. Although controversial, IL-15 has the advantage of having synergistic effect with different cytokines 
[5, 93, 104]. Simultaneous coexpression of IL-15 and IL-21 in CAR $\mathrm{T}$ cells enriched for less-differentiated $\mathrm{T}$ cells by sustaining TCF1 expression, a transcription factor associated with higher percentage of stem cell memory and central memory populations [104]. In addition, IL-18secreting CAR T cells have exhibited a boosted proliferation and antitumor activity, describing the IL-18 influence on the CAR T cell function and persistence [103, 105].

\section{Change in the milieu of TME}

External suppressive signals (i.e., TGF- $\beta$, IL-10, PGE2, soluble FAS, adenosine, ROS) from stromal and suppressive immune cells such as cancer associated fibroblasts (CAFs), myeloid-derived suppressor cells (MDSCs), tumor associated macrophages (TAMs), tumor associated neutrophils, mast cells, and regulatory $\mathrm{T}$ cells $\left(\mathrm{T}_{\text {reg }}\right)$ contribute to the initiation of exhaustion of CAR $\mathrm{T}$ cells [106]. However, also tumor cells produce many of these suppressive mediators in the TME (i.e., PD-L1, TGF- $\beta$, IL-10, PGE2) to counteract effective immune responses. Activation of negative signals in tumor cells synergizes with the function of suppressive cells in the TME and can additionally induce a plethora of immunosuppressive pathways that may lead to the CAR T cell dysfunction [107]. Several efforts have been made to interfere with these suppressive signals activated by either tumoral or non-tumoral cells to make the TME milieu more tolerable for CAR T cells. Long and colleagues modulated MDSCs by all-trans retinoic acid (ATRA) molecule to diminish the suppressive effect of these cells on CAR T cells. Co-administration of ATRA enhanced antitumor effect of CAR T cells and prolonged their survival in vivo [108]. Aiming to eliminate MDSCs from the TME, Parihar et al. described a creative strategy by means of NKG2D-based CAR NK cells. The authors found that pretreatment of xenograft model with the modified NK cells resisted CAR $\mathrm{T}$ cells to the TME suppression, and improved tumor infiltration and efficacy of CAR $\mathrm{T}$ cells through killing NKG2D ligand-expressing tumor cells and MDSCs. Of note, administration of CAR T cells alone could not prevent tumor growth due to the suppressive signals from tumor-infiltrated MDSCs [109]. Blockade of suppressor cells in the TME can also lead to the elimination of immune checkpoint signaling, as these cells are an important source of immune checkpoint ligands (i.e., PDL1). In concordance with this, targeting PD-L1-positive MDSCs and $\mathrm{T}_{\text {regs }}$ in the TME prevented CAR T cell suppression by these cells' immunosuppressive pathways, and augmented the efficacy of CAR T cell therapy [110]. Some studies have focused on the enhancement of CAR $T$ cell resistance to the suppressor cells, rather than direct targeting of suppressor cells. As an instance, CAR $\mathrm{T}$ cells with constitutive or induced expression of IL-12 switched to the resistant cells with less susceptibility to $\mathrm{T}_{\text {regs }}$, MDSCs, and TAMs [111-113]. Notably, the IL-12-mediated stromal collapse was associated with the upregulation of FAS death receptors on MDSCs, macrophages, and dendritic cells (DCs) within the tumor stroma [112].

Targeting specific surface markers of cancer-associated stromal cells (CASCs) such as PD-L1 have the potential to reinforce CAR $\mathrm{T}$ cell therapies in tumor site by collapsing dense stromal components [114]. In an effort, coadministration of CAR $\mathrm{T}$ cells with oncolytic adenoviruses expressing PD-L1 blocking antibodies not only resulted in further antitumor activity, but also diminished the expression of PD- 1 on the surface of CAR T cells [115]. In addition, tumor site-specific delivery of PD-L1 antibody by CAR $\mathrm{T}$ cells could impede the cell exhaustion and diminish tumor growth much better than conventional CAR $\mathrm{T}$ cells [116]. In an interesting approach, PD-L1 in the TME was targeted as an antigen via nanobody-based CAR $\mathrm{T}$ cells. The PD-L1-targeted CAR T cells successfully controlled tumor growth and alleviated the expression of exhaustion markers such as LAG-3, TIM-3, and PD-1 [114]. This approach has two advantages of activating local antitumor response in the TME and eliminating CASCs, simultaneously. As highlighted above, TGF- $\beta$ is another critical suppressor of effector $\mathrm{T}$ cells that is produced by major cell compartments in the TME. Thus, antagonizing this ligand may benefit cancer immunotherapies [80]. Efforts including, CD28 or cytokine costimulation, expression of constitutively active AKT, expression of dominant negative TGF- $\beta$ receptors, or design of TGF$\beta$-based decoy CARs have been carried out to overcome TGF- $\beta$-mediated repression of CAR $\mathrm{T}$ cells [117]. In addition to PD-L1 and TGF- $\beta$, tumor cells and some immune cells in the TME can further suppress CAR T cells by expressing IDO, an intracellular enzyme that converts the amino acid tryptophan to the kynurenine. The immunosuppressive kynurenine subsequently increases $\mathrm{T}_{\text {regs }}$ population and biases the TME's cells (i.e., DCs and macrophages) toward an immunosuppressive phenotype through activating the receptor AhR [118-120]. Downregulation of IDO by fludarabine and cyclophosphamide, two lymphodepleting drugs often used before CAR T cell infusion, significantly improved the efficacy of CAR T cell therapy in IDO-positive tumors [121]. The serine protease FAP, which is highly expressed by CASCs like CAFs, may also play an important role in alleviation of antitumor immunity. Direct targeting of this protease using CAR approach has shown to be safe and effective for depleting the FAP ${ }^{\mathrm{hi}}$ stromal cells and enhancing CAR T cell function [122]. Lately, FAP-specific CAR T cells advanced into a phase I clinical trial for treatment of patients with malignant pleural mesothelioma (NCT01722149). TAMs, particularly 
M2 polarized macrophages, express several specific markers that can be modulated by CAR-based modalities. CSF1R is one of such TAM biomarkers that was recently targeted using CAR T and CAR NK platforms, and represented a promising potential for depletion of the suppressive TAMs [123]. Further TAM biomarkers (i.e., MARCO, FR $\beta$ ) are also being interrogated as potential candidates for TAM targeting to establish optimal CAR $\mathrm{T}$ immunotherapies [124].

It should be noted that metabolic changes in the TME can enforce the exhausted phenotype of CAR $\mathrm{T}$ cells. Indeed, due to the limited vascular exchange and metabolism of tumor cells leading to a microenvironment with acidic, hypoxic and/or depleted nutrients (e.g., glucose, amino acids), the TME is metabolically hostile [125]. Metabolic dysfunction in the tumor site linked to early inhibitory signals can enhance the development of $\mathrm{T}$ cell exhaustion [126]. As it happens with cancer cells, $\mathrm{T}$ cell metabolism is totally dependent on the composition of the TME, which may enable the necessary activity levels of aerobic glycolysis, pentose phosphate and tricarboxylic acid pathways required for $\mathrm{T}$ cell proliferation and function. For instance, under low-glucose conditions $\mathrm{T}$ cells produce lower levels of effector molecules such as IFN $\gamma$, granzyme $\mathrm{B}$, and IL-7 [127, 128]. Another important aspect is mitochondrial integrity and number, which is crucial for effector cells. Exhausted tumor-infiltrating $\mathrm{T}$ cells show signs of mitochondrial dysfunction that correlate with reduced activity of PGC1 $\alpha$ and the antitumor activity could be rescued by through overexpression of PGC1 $\alpha$ [129]. Furthermore, production of immunosuppressive metabolites also contributes to the effector dysfunction of $\mathrm{T}$ cells. As an example, adenosine is a key metabolic regulator implicated in the $\mathrm{T}$ cell exhaustion. This metabolite is generated by the ectonucleotidases CD39 and CD73 and has a critical role in mediating suppressive effects of stromal cells, tumor cells, and infiltrating immune cells [75]. Hence, pharmacologic or genetic metabolic reprogramming of either the TME cells or CAR T cells is beginning to accrue. To this end, potential targets have been identified such as IDO, ARG1, CD36, CD39, CD73, GLS, A2AR, AMPK, and PDHK1 [130].

\section{Safety considerations and concluding remarks}

It should be pointed out that reversing or delaying exhaustion and senescence in CAR T cells is a two-edged sword. Regardless of impressive efficacy of reinvigorated CAR $\mathrm{T}$ cells, a risk assessment of unexpected toxicities has remained to be investigated [11]. "On-target, on-tumor" toxicity can be a direct consequence of reinvigorated CAR $\mathrm{T}$ cells, which is related to the induction of CRS and tumor lysis syndrome induced by abundant cytokine release and excessive tumor cell death in tumor site [131]. On the other hand, a catastrophic and rapid "on-target, off-tumor" toxicity might be observed after infusion of armored CAR T cells targeting a tumor-associated antigen (TAA), which is expressed in both tumor and normal cells. This is the most serious complication of armored CAR T cells that results from a direct attack to the TAAs as well as long-term circulation and persistence of armored CAR T cells [131, 132]. Although controversial, senescence is considered to be a crucial obstacle against cancer development, and blockade of senescence drivers in tumor site may therefore be procarcinogenic [133, 134]. Taken together, there is a concern regarding the side effects associated with exhaustion/senescence-resistant CAR T cells. To avoid these adverse effects in modified CAR T cells, further developments need to be considered [135]. For instance, some researchers recommend to insert an inducible "suicide gene" or "elimination gene" (e.g., HSV-TK, inducible caspase 9, truncated EGFR, TMPK) into the CAR $T$ cell genome that renders CAR $\mathrm{T}$ cells susceptible to an exogenous molecule-mediated death in case of adverse effects [136].

In conclusion, the field of cancer immunotherapy has undergone a revolution, with the development of adoptive cell transfer (ACT) therapies and immune checkpoint inhibitors (ICIs) leading the way in improving the outcome of cancer therapy. Nevertheless, the ability of the immune system to fight tumors in the hostile TME remains a major challenge for both ICIs and ACT therapies, particularly when it comes to various types of solid tumors. Here we summarized how the efficacy of CAR T cell therapy is restricted by the activation of exhaustion and senescence pathways, and what efforts have been made to reinvigorate dysfunctional CAR T cells. As research on CAR T cell dysfunction, especially in relation to the senescence, is a relatively new field and experimental data is limited, this review largely focuses on CAR T cell exhaustion. Approaches to delay the exhaustion/senescence in CAR T cells include direct modulation of intrinsic pathways and/or harnessing exogenous signals. Costimulation induction and cytokine exposure as well as attenuation of TME's suppressive milieu appears to be feasible in this context. The efficacy and scalability of much of what has been discussed here is not limited to the CAR $\mathrm{T}$ cells, and can also be developed to other types of $\mathrm{T}$ cells therapies such as tumorinfiltrating lymphocytes (TILs) or TCR-engineered $\mathrm{T}$ (TCR-T) cells. However, further investigations into the safety of these platforms have to be taken into consideration.

Acknowledgements MP was supported by a postdoctoral fellowship from Rolf Kiessling's project grant from the Swedish Cancer Society (CAN2016/315). He is now an Alexander von Humboldt fellow. ACA gratefully acknowledges Prof. Harald zur Hausen for his continuous scientific support and encouragement. 


\section{Compliance with ethical standards}

Conflict of interest The authors declare that there is no conflict of interest.

Publisher's note Springer Nature remains neutral with regard to jurisdictional claims in published maps and institutional affiliations.

Open Access This article is licensed under a Creative Commons Attribution 4.0 International License, which permits use, sharing, adaptation, distribution and reproduction in any medium or format, as long as you give appropriate credit to the original author(s) and the source, provide a link to the Creative Commons license, and indicate if changes were made. The images or other third party material in this article are included in the article's Creative Commons license, unless indicated otherwise in a credit line to the material. If material is not included in the article's Creative Commons license and your intended use is not permitted by statutory regulation or exceeds the permitted use, you will need to obtain permission directly from the copyright holder. To view a copy of this license, visit http://creativecommons. org/licenses/by/4.0/.

\section{References}

1. Poorebrahim M, Abazari MF, Sadeghi S, Mahmoudi R, Kheirollahi A, Askari H, et al. Genetically modified immune cells targeting tumor antigens. Pharmacol Ther. 2020;214: 107603.

2. Park JH, Rivière I, Gonen M, Wang X, Sénéchal B, Curran KJ, et al. Long-term follow-up of CD19 CAR therapy in acute lymphoblastic leukemia. N Engl J Med. 2018;378:449-59.

3. Maude SL, Laetsch TW, Buechner J, Rives S, Boyer M, Bittencourt $\mathrm{H}$, et al. Tisagenlecleucel in children and young adults with B-cell lymphoblastic leukemia. N Engl J Med. 2018;378:439-48.

4. Shah NN, Fry TJ. Mechanisms of resistance to CAR T cell therapy. Nat Rev. Clin Oncol. 2019;16:372-85.

5. Alizadeh D, Wong RA, Yang X, Wang D, Pecoraro JR, Kuo C-F, et al. IL15 enhances CAR-T cell antitumor activity by reducing mTORC1 activity and preserving their stem cell memory phenotype. Cancer. Immunol Res. 2019;7:759-72.

6. Ye B, Stary CM, Li X, Gao Q, Kang C, Xiong X. Engineering chimeric antigen receptor-T cells for cancer treatment. Mol Cancer. 2018;17:32.

7. Long AH, Haso WM, Shern JF, Wanhainen KM, Murgai M, Ingaramo $\mathrm{M}$, et al. 4-1BB costimulation ameliorates $\mathrm{T}$ cell exhaustion induced by tonic signaling of chimeric antigen receptors. Nat Med. 2015;21:581-90.

8. Wherry EJ, Kurachi M. Molecular and cellular insights into T cell exhaustion. Nat Rev Immunol. 2015;15:486-99.

9. Rafiq S, Yeku OO, Jackson HJ, Purdon TJ, van Leeuwen DG, Drakes DJ, et al. Targeted delivery of a PD-1-blocking scFv by CAR-T cells enhances anti-tumor efficacy in vivo. Nat Biotechnol. 2018;36:847-56.

10. Chen J, López-Moyado IF, Seo H, Lio CJ, Hempleman LJ, Sekiya T, et al. NR4A transcription factors limit CAR T cell function in solid tumours. Nature. 2019;567:530-4.

11. Lynn RC, Weber EW, Sotillo E, Gennert D, Xu P, Good Z, et al. c-Jun overexpression in CAR T cells induces exhaustion resistance. Nature. 2019;576:293-300.

12. Appay V, Dunbar PR, Callan M, Klenerman P, Gillespie GM, Papagno $\mathrm{L}$, et al. Memory CD8+. T cells vary in differentiation phenotype in different persistent virus infections. Nat Med. 2002;8:379-85.

13. Wherry EJ. T cell exhaustion. Nat Immunol. 2011;12:492-9.

14. Zhao Y, Shao Q, Peng G. Exhaustion and senescence: two crucial dysfunctional states of $\mathrm{T}$ cells in the tumor microenvironment. Cell Mol Immunol. 2020;17:27-35.

15. Beltra JC, Manne S, Abdel-Hakeem MS, Kurachi M, Giles JR, Chen Z, et al. Developmental relationships of four exhausted $\mathrm{CD} 8(+) \mathrm{T}$ cell subsets reveals underlying transcriptional and epigenetic landscape control mechanisms. Immunity. 2020;19: 825-41.e8.

16. Akbar AN, Henson SM. Are senescence and exhaustion intertwined or unrelated processes that compromise immunity?. Nat Rev Immunol. 2011;11:289-95.

17. Leclerc M, Voilin E, Gros G, Corgnac S, de Montpréville V, Validire P, et al. Regulation of antitumour CD8+ T-cell immunity and checkpoint blockade immunotherapy by Neuropilin-1. Nat Commun. 2019;10:1-14.

18. Wherry EJ, Ha S-J, Kaech SM, Haining WN, Sarkar S, Kalia V, et al. Molecular signature of CD8+. T cell exhaustion during chronic viral infection. 2007;27:670-84.

19. Hernandez-Segura A, Nehme J, Demaria M. Hallmarks of cellular senescence. Trends Cell Biol. 2018;28:436-53.

20. Sharpless NE, Sherr CJ. Forging a signature of in vivo senescence. Nat Rev Cancer. 2015;15:397-408.

21. Liu X, Hoft DF, Peng G. Senescent T cells within suppressive tumor microenvironments: emerging target for tumor immunotherapy. J Clin Investig. 2020;130:1073-83.

22. Brenchley JM, Karandikar NJ, Betts MR, Ambrozak DR, Hill BJ, Crotty LE, et al. Expression of CD57 defines replicative senescence and antigen-induced apoptotic death of CD8+ T cells. Blood. 2003;101:2711-20.

23. Garrod KR, Moreau HD, Garcia Z, Lemaître F, Bouvier I, Albert ML, et al. Dissecting $T$ cell contraction in vivo using a genetically encoded reporter of apoptosis. Cell Rep. 2012;2:1438-47.

24. Gorgoulis V, Adams PD, Alimonti A, Bennett DC, Bischof O, Bishop C, et al. Cellular senescence: defining a path forward. Cell. 2019;179:813-27.

25. Davis T, Bagley MC, Dix MC, Murziani PG, Rokicki MJ, Widdowson CS, et al. Synthesis and in vivo activity of MK2 and MK2 substrate-selective p38alpha(MAPK) inhibitors in Werner syndrome cells. Bioorg Med Chem Lett. 2007;17:6832-5.

26. Blackburn SD, Shin H, Haining WN, Zou T, Workman CJ, Polley A, et al. Coregulation of $\mathrm{CD} 8+$. $\mathrm{T}$ cell exhaustion by multiple inhibitory receptors during chronic viral infection. Nat Immunol. 2009;10:29

27. Ligtenberg MA, Pico de Coaña Y, Shmushkovich T, Yoshimoto Y, Truxova I, Yang Y, et al. Self-delivering RNAi targeting PD1 improves tumor-specific $\mathrm{T}$ cell functionality for adoptive cell therapy of malignant melanoma. Mol Ther: J Am Soc Gene Ther. 2018;26:1482-93.

28. John LB, Devaud C, Duong CP, Yong CS, Beavis PA, Haynes $\mathrm{NM}$, et al. Anti-PD-1 antibody therapy potently enhances the eradication of established tumors by gene-modified T cells. Clin Cancer Res. 2013;19:5636-46.

29. Cherkassky L, Morello A, Villena-Vargas J, Feng Y, Dimitrov DS, Jones DR, et al. Human CAR T cells with cell-intrinsic PD-1 checkpoint blockade resist tumor-mediated inhibition. J Clin Investig. 2016;126:3130-44.

30. Huang B, Luo L, Wang J, He B, Feng R, Xian N, et al. B7-H3 specific $\mathrm{T}$ cells with chimeric antigen receptor and decoy PD-1 receptors eradicate established solid human tumors in mouse models. Oncoimmunology. 2019:1684127.

31. Rupp LJ, Schumann K, Roybal KT, Gate RE, Ye CJ, Lim WA, et al. CRISPR/Cas9-mediated PD-1 disruption enhances anti- 
tumor efficacy of human chimeric antigen receptor T cells. Sci Rep. 2017;7:737.

32. Odorizzi PM, Pauken KE, Paley MA, Sharpe A, Wherry EJ. Genetic absence of PD-1 promotes accumulation of terminally differentiated exhausted CD8+ $\mathrm{T}$ cells. $\mathrm{J}$ Exp Med. 2015;212:1125-37.

33. Yin Y, Boesteanu AC, Binder ZA, Xu C, Reid RA, Rodriguez $\mathrm{JL}$, et al. Checkpoint blockade reverses anergy in IL-13R $\alpha 2$ humanized $\mathrm{scFv}$-based CAR $\mathrm{T}$ cells to treat murine and canine gliomas. Mol Ther Oncolytics. 2018;11:20-38.

34. Ren J, Zhang X, Liu X, Fang C, Jiang S, June CH, et al. A versatile system for rapid multiplex genome-edited CAR $\mathrm{T}$ cell generation. Oncotarget. 2017;8:17002-11.

35. Zou F, Lu L, Liu J, Xia B, Zhang W, Hu Q, et al. Engineered triple inhibitory receptor resistance improves anti-tumor CAR-T cell performance via CD56. Nat Commun. 2019;10:1-14.

36. Anderson AC, Joller N, Kuchroo VK. Lag-3, Tim-3, and TIGIT: co-inhibitory receptors with specialized functions in immune regulation. Immunity. 2016;44:989-1004.

37. Yazdanifar M, Zhou R, Grover P, Williams C, Bose M, Moore $\mathrm{LJ}$, et al. Overcoming immunological resistance enhances the efficacy of a novel anti-tMUC1-CAR $\mathrm{T}$ cell treatment against pancreatic ductal adenocarcinoma. Cells. 2019;11;8:1070.

38. Wang J, Sanmamed MF, Datar I, Su TT, Ji L, Sun J, et al. Fibrinogen-like Protein 1 is a major immune inhibitory ligand of LAG-3. Cell. 2019;176:334-47.e312.

39. Bae J, Lee SJ, Park CG, Lee YS, Chun T. Trafficking of LAG-3 to the surface on activated $\mathrm{T}$ cells via its cytoplasmic domain and protein kinase C signaling. J Immunol. 2014;193:3101-12.

40. Marro BS, Zak J, Zavareh RB, Teijaro JR, Lairson LL, Oldstone MBA. Discovery of small molecules for the reversal of $\mathrm{T}$ cell exhaustion. Cell Rep. 2019;29:3293-3302.e3293.

41. Hui E, Cheung J, Zhu J, Su X, Taylor MJ, Wallweber HA, et al. $\mathrm{T}$ cell costimulatory receptor $\mathrm{CD} 28$ is a primary target for PD-1mediated inhibition. Science. 2017;355:1428-33.

42. Kong K-F, Yokosuka T, Canonigo-Balancio AJ, Isakov N, Saito T, Altman A. A motif in the V3 domain of the kinase PKC- $\theta$ determines its localization in the immunological synapse and functions in $\mathrm{T}$ cells via association with CD28. Nat Immunol. 2011;12:1105.

43. Schorer M, Rakebrandt N, Lambert K, Hunziker A, Pallmer K, Oxenius A, et al. TIGIT limits immune pathology during viral infections. Nat Commun. 2020;11:1-14.

44. Song Y, Wang B, Song R, Hao Y, Wang D, Li Y, et al. T-cell Immunoglobulin and ITIM domain contributes to CD $8+$. T-cell Immunosenescence. Aging Cell. 2018;17:e12716.

45. Hoogi S, Eisenberg V, Mayer S, Shamul A, Barliya T, Cohen CJ. A TIGIT-based chimeric co-stimulatory switch receptor improves T-cell anti-tumor function. J Immunother Cancer. 2019;7:243.

46. Man K, Gabriel SS, Liao Y, Gloury R, Preston S, Henstridge $\mathrm{DC}$, et al. Transcription factor IRF4 promotes CD8+. T cell exhaustion and limits the development of memory-like $\mathrm{T}$ cells during chronic infection. Immunity. 2017;47:e1125.

47. Liu X, Wang Y, Lu H, Li J, Yan X, Xiao M, et al. Genome-wide analysis identifies NR4A1 as a key mediator of T cell dysfunction. Nature. 2019;567:525-9.

48. Jia B, Zhao C, Rakszawski KL, Claxton DF, Ehmann WC, Rybka WB, et al. Eomes+ T-betlow CD8+. T cells are functionally impaired and are associated with poor clinical outcome in patients with acute myeloid leukemia. Cancer Res. 2019;79:1635-45.

49. Li J, He Y, Hao J, Ni L, Dong C. High levels of eomes promote exhaustion of anti-tumor CD8+. T cells. Front Immunol. 2018;9:2981.
50. Chmielewski M, Abken H. CAR T cells releasing IL-18 convert to T-Bethigh FoxO1low effectors that exhibit augmented activity against advanced solid tumors. Cell Rep. 2017;21:3205-19.

51. Chong EA, Melenhorst JJ, Lacey SF, Ambrose DE, Gonzalez V, Levine BL, et al. PD-1 blockade modulates chimeric antigen receptor (CAR)-modified $\mathrm{T}$ cells: refueling the CAR. Blood. 2017;129:1039-41.

52. Wilkinson B, Chen JY, Han P, Rufner KM, Goularte OD, Kaye J. TOX: an HMG box protein implicated in the regulation of thymocyte selection. Nat Immunol. 2002;3:272-80.

53. Wang X, He Q, Shen H, Xia A, Tian W, Yu W, et al. TOX promotes the exhaustion of antitumor $\mathrm{CD} 8+. \mathrm{T}$ cells by preventing PD1 degradation in hepatocellular carcinoma. J Hepatol. 2019;71:731-41.

54. Khan O, Giles JR, McDonald S, Manne S, Ngiow SF, Patel KP, et al. TOX transcriptionally and epigenetically programs $\mathrm{CD} 8(+)$ T cell exhaustion. Nature. 2019;571:211-8.

55. Seo H, Chen J, González E, Samaniego-Castruita D, Das A, Wang YH, et al. TOX and TOX2 transcription factors cooperate with NR4A transcription factors to impose CD8+. T cell exhaustion. Proc Natl Acad Sci USA. 2019;116:12410-5.

56. Kim EH, Sullivan JA, Plisch EH, Tejera MM, Jatzek A, Choi $\mathrm{KY}$, et al. Signal integration by Akt regulates $\mathrm{CD} 8+\mathrm{T}$ cell effector and memory differentiation. $\mathbf{J}$ Immunol. 2012;188:4305-14.

57. Klebanoff CA, Crompton JG, Leonardi AJ, Yamamoto TN, Chandran SS, Eil RL, et al. Inhibition of AKT signaling uncouples $\mathrm{T}$ cell differentiation from expansion for receptorengineered adoptive immunotherapy. JCI Insight. 2017;7;2: e95103.

58. Zheng W, O'Hear CE, Alli R, Basham JH, Abdelsamed HA, Palmer LE, et al. PI3K orchestration of the in vivo persistence of chimeric antigen receptor-modified $\mathrm{T}$ cells. Leukemia. 2018;32:1157-67.

59. Abu Eid R, Ahmad S, Lin Y, Webb M, Berrong Z, Shrimali R, et al. Enhanced therapeutic efficacy and memory of tumorspecific CD8 $+\mathrm{T}$ cells by ex vivo PI3K- $\delta$ inhibition. Cancer Res. 2017;77:4135-45.

60. Wentink MWJ, Mueller YM, Dalm V, Driessen GJ, van Hagen PM, van Montfrans JM, et al. Exhaustion of the CD8(+) T cell compartment in patients with mutations in phosphoinositide 3kinase delta. Front Immunol. 2018;9:446.

61. Bowers JS, Majchrzak K, Nelson MH, Aksoy BA, Wyatt MM, Smith AS, et al. PI3K $\delta$ inhibition enhances the antitumor fitness of adoptively transferred $\mathrm{CD} 8(+) \mathrm{T}$ cells. Front Immunol. 2017;8:1221.

62. Leontieva OV, Blagosklonny MV. DNA damaging agents and p53 do not cause senescence in quiescent cells, while consecutive re-activation of mTOR is associated with conversion to senescence. Aging. 2010;2:924-35.

63. Blagosklonny MV. Cell cycle arrest is not yet senescence, which is not just cell cycle arrest: terminology for TOR-driven aging. Aging. 2012;4:159-65.

64. Staron MM, Gray SM, Marshall HD, Parish IA, Chen JH, Perry $\mathrm{CJ}$, et al. The transcription factor FoxO1 sustains expression of the inhibitory receptor PD-1 and survival of antiviral CD8+. T cells during chronic infection. Immunity. 2014;41:802-14.

65. Rao RR, Li Q, Gubbels Bupp MR, Shrikant PA. Transcription factor Foxo1 represses T-bet-mediated effector functions and promotes memory $\mathrm{CD} 8(+) \mathrm{T}$ cell differentiation. Immunity. 2012;36:374-87.

66. LaFleur MW, Nguyen TH, Coxe MA, Miller BC, Yates KB, Gillis JE, et al. PTPN2 regulates the generation of exhausted $\mathrm{CD} 8(+) \mathrm{T}$ cell subpopulations and restrains tumor immunity. Nat Immunol. 2019;20:1335-47. 
67. Parry RV, Chemnitz JM, Frauwirth KA, Lanfranco AR, Braunstein I, Kobayashi SV, et al. CTLA-4 and PD-1 receptors inhibit T-cell activation by distinct mechanisms. Mol Cell Biol. 2005;25:9543-53.

68. Wiede F, Lu KH, Du X, Liang S, Hochheiser K, Dodd GT, et al. PTPN2 phosphatase deletion in $\mathrm{T}$ cells promotes anti-tumour immunity and CAR T-cell efficacy in solid tumours. EMBO J. 2020;39:e103637.

69. Cui J, Wang H, Medina R, Zhang Q, Xu C, Indig IH, et al. Inhibition of PP2A with LB-100 enhances efficacy of CAR-T cell therapy against glioblastoma. Cancers 2020; 12.

70. Sun C, Shou P, Du H, Hirabayashi K, Chen Y, Herring LE, et al. THEMIS-SHP1 recruitment by 4-1BB tunes LCK-mediated priming of chimeric antigen receptor-redirected $\mathrm{T}$ cells. Cancer Cell. 2020;37:216-25. e216.

71. Rota G, Niogret C, Dang AT, Barros CR, Fonta NP, Alfei F, et al. Shp-2 is dispensable for establishing T cell exhaustion and for PD-1 signaling in vivo. Cell Rep. 2018;23:39-49.

72. Yokosuka T, Takamatsu M, Kobayashi-Imanishi W, HashimotoTane A, Azuma M, Saito T. Programmed cell death 1 forms negative costimulatory microclusters that directly inhibit $\mathrm{T}$ cell receptor signaling by recruiting phosphatase SHP2. J Exp Med. 2012;209:1201-17.

73. Moon E, Kim S, Saint Jean N, O'Brien S, Maceyko S, Sun J, et al. Genetic blockade of the protein tyrosine phosphatase SHP1 augments CAR $\mathrm{T}$ cell activity against PDL1 expressing solid tumors. AACR. 2017;77:13.

74. Petersen C, Bell M, Houke H, Yi Z, Gottschalk S, Krenciute G. IMMU-13. CRISPR/CAS9-mediated silencing of shp-1 significantly enhances the anti-glioma activity of IL-13R $\alpha 2$ CAR T cells. Neuro-Oncology. 2019;21:ii95.

75. Allard B, Longhi MS, Robson SC, Stagg J. The ectonucleotidases CD39 and CD73: Novel checkpoint inhibitor targets. Immunol Rev. 2017;276:121-44.

76. Masoumi E, Jafarzadeh L, Mirzaei HR, Alishah K, FallahMehrjardi K, Rostamian H, et al. Genetic and pharmacological targeting of A2a receptor improves function of anti-mesothelin CAR T cells. J Exp Clin cancer Res. 2020;39:49.

77. Young A, Ngiow SF, Barkauskas DS, Sult E, Hay C, Blake SJ, et al. Co-inhibition of CD73 and A2AR adenosine signaling improves antitumor immune responses. Cancer Cell. 2016;30:391-403.

78. Beavis PA, Henderson MA, Giuffrida L, Mills JK, Sek K, Cross $\mathrm{RS}$, et al. Targeting the adenosine $2 \mathrm{~A}$ receptor enhances chimeric antigen receptor T cell efficacy. J Clin Investig. 2017;127: 929-41.

79. Newick K, O’Brien S, Sun J, Kapoor V, Maceyko S, Lo A, et al. Augmentation of CAR T-cell trafficking and antitumor efficacy by blocking protein kinase A localization. Cancer Immunol Res. 2016;4:541-51.

80. Loffek S. Transforming of the tumor microenvironment: implications for TGF-beta Inhibition in the context of immunecheckpoint therapy. J Oncol. 2018;2018:9732939.

81. Batlle E, Massagué, J. Transforming growth factor- $\beta$ signaling in immunity and cancer. Immunity. 2019;50:924-40.

82. Tang N, Cheng C, Zhang X, Qiao M, Li N, Mu W, et al. TGF- $\beta$ inhibition via CRISPR promotes the long-term efficacy of CAR T cells against solid tumors. JCI Insight. 2020;27;5:e133977.

83. Kloss CC, Lee J, Zhang A, Chen F, Melenhorst JJ, Lacey SF, et al. Dominant-negative TGF- $\beta$ receptor enhances PSMAtargeted human CAR T cell proliferation and augments prostate cancer eradication. Mol Ther: J Am Soc Gene Ther. 2018;26:1855-66.

84. Boyerinas B, Miller SM, Murray RC, Evans JW, Parsons GB, Seidl KJ, et al. A novel TGF- $\beta_{2}$ /interleukin receptor signal conversion platform that protects CAR/TCR T cells from TGF- $\beta_{2}$-mediated immune suppression and induces $\mathrm{T}$ cell supportive signaling networks. Blood. 2017;130:1911.

85. Roth A, Yssel H, Pene J, Chavez EA, Schertzer M, Lansdorp $\mathrm{PM}$, et al. Telomerase levels control the lifespan of human $\mathrm{T}$ lymphocytes. Blood. 2003;102:849-57.

86. Luiten RM, Pene J, Yssel H, Spits H. Ectopic hTERT expression extends the life span of human $\mathrm{CD} 4+$ helper and regulatory $\mathrm{T}$ cell clones and confers resistance to oxidative stress-induced apoptosis. Blood. 2003;101:4512-9.

87. Bai Y, Kan S, Zhou S, Wang Y, Xu J, Cooke JP, et al. Enhancement of the in vivo persistence and antitumor efficacy of CD19 chimeric antigen receptor T cells through the delivery of modified TERT mRNA. Cell Discov. 2015;1:15040.

88. Sies H, Jones DP. Reactive oxygen species (ROS) as pleiotropic physiological signalling agents. Nat Rev Mol Cell Biol. 2020:1-21.

89. Bengsch B, Johnson AL, Kurachi M, Odorizzi PM, Pauken KE, Attanasio $J$, et al. Bioenergetic insufficiencies due to metabolic alterations regulated by the inhibitory receptor PD-1 are an early driver of CD8 +. T cell exhaustion. Immunity. 2016;45:358-73.

90. Ligtenberg MA, Mougiakakos D, Mukhopadhyay M, Witt K, Lladser A, Chmielewski M, et al. Coexpressed catalase protects chimeric antigen receptor-redirected $\mathrm{T}$ cells as well as bystander cells from oxidative stress-induced loss of antitumor activity. 2016;196:759-66.

91. Yoo HJ, Liu Y, Wang L, Schubert ML, Hoffmann JM, Wang S, et al. Tumor-specific reactive oxygen species accelerators improve chimeric antigen receptor $\mathrm{T}$ cell therapy in B cell malignancies. Int J Mol Sci. 2019:18;20:2469.

92. Guedan S, Posey AD, Jr, Shaw C, Wing A, Da T, Patel PR, et al. Enhancing CAR T cell persistence through ICOS and 4-1BB costimulation. JCI Insight. 2018:11;3:e96976.

93. Xu Y, Zhang M, Ramos CA, Durett A, Liu E, Dakhova O, et al. Closely related T-memory stem cells correlate with in vivo expansion of CAR.CD19-T cells and are preserved by IL-7 and IL-15. Blood. 2014;123:3750-9.

94. Singh H, Figliola MJ, Dawson MJ, Huls H, Olivares S, Switzer $\mathrm{K}$, et al. Reprogramming CD19-specific T cells with IL-21 signaling can improve adoptive immunotherapy of B-lineage malignancies. Cancer Res. 2011;71:3516-27.

95. van der Stegen SJ, Hamieh M, Sadelain M. The pharmacology of second-generation chimeric antigen receptors. Nat Rev Drug Discov. 2015;14:499-509.

96. Guedan S, Chen X, Madar A, Carpenito C, McGettigan SE, Frigault MJ, et al. ICOS-based chimeric antigen receptors program bipolar TH17/TH1 cells. Blood. 2014;124:1070-80.

97. Gomes-Silva D, Mukherjee M, Srinivasan M, Krenciute G, Dakhova O, Zheng Y, et al. Tonic 4-1BB costimulation in chimeric antigen receptors impedes $\mathrm{T}$ cell survival and is vectordependent. Cell Rep. 2017;21:17-26.

98. Li G, Boucher JC, Kotani H, Park K, Zhang Y, Shrestha B, et al. 4-1BB enhancement of CAR $T$ function requires $N F-\kappa B$ and TRAFs. JCI Insight 2018:20;3:e121322.

99. Philipson BI, O'Connor RS, May MJ, June CH, Albelda SM, Milone MC. 4-1BB costimulation promotes CAR T cell survival through noncanonical NF-kappa B signaling. Sci Signal. 2020:31;13:eaay8248.

100. Guedan S, Madar A, Casado-Medrano V, Shaw CE, Wing A, Liu $\mathrm{F}$ et al. Single residue in CD28-costimulated CAR T cells limits long-term persistence and antitumor durability. J Clin Investig. 2020.

101. Warrington KJ, Vallejo AN, Weyand CM, Goronzy JJ. CD28 losspersistence and antitumor durability in senescent CD4+ $\mathrm{T}$ cells: reversal by interleukin-12 stimulation. Blood. 2003;101:3543-9. 
102. Zhou J, Jin L, Wang F, Zhang Y, Liu B, Zhao T. Chimeric antigen receptor $\mathrm{T}$ (CAR-T) cells expanded with IL-7/IL-15 mediate superior antitumor effects. Protein Cell. 2019;10:764-9.

103. Hu B, Ren J, Luo Y, Keith B, Young RM, Scholler J, et al. Augmentation of antitumor immunity by human and mouse CAR T cells secreting IL-18. Cell Rep. 2017;20:3025-33.

104. Batra SA, Rathi P, Guo L, Courtney AN, Fleurence J, Balzeau J, et al. Glypican-3-specific CAR T cells co-expressing IL15 and IL21 have superior expansion and antitumor activity against hepatocellular carcinoma. Cancer Immunol Res. 2020:8:309-320.

105. Chmielewski M, Abken H. CAR T cells releasing IL-18 convert to T-Bet(high) FoxO1(low) effectors that exhibit augmented activity against advanced solid tumors. Cell Rep. 2017;21: 3205-19.

106. Martinez M, Moon EK. CAR T cells for solid tumors: new strategies for finding, infiltrating, and surviving in the tumor microenvironment. Front Immunol. 2019;10:128.

107. Rabinovich GA, Gabrilovich D, Sotomayor EM. Immunosuppressive strategies that are mediated by tumor cells. Annu Rev Immunol. 2007;25:267-96.

108. Long AH, Highfill SL, Cui Y, Smith JP, Walker AJ, Ramakrishna $\mathrm{S}$, et al. Reduction of MDSCs with all-trans retinoic acid improves CAR therapy efficacy for sarcomas. Cancer Immunol Res. 2016;4:869-80.

109. Parihar R, Rivas C, Huynh M, Omer B, Lapteva N, Metelitsa LS, et al. NK cells expressing a chimeric activating receptor eliminate MDSCs and rescue impaired CAR-T cell activity against solid tumors. Cancer Immunol Res. 2019;7:363-75.

110. Katz SC, Point GR, Cunetta M, Thorn M, Guha P, Espat NJ, et al. Regional CAR-T cell infusions for peritoneal carcinomatosis are superior to systemic delivery. Cancer Gene Ther. 2016;23:142-8.

111. Kerkar SP, Goldszmid RS, Muranski P, Chinnasamy D, Yu Z, Reger RN, et al. IL-12 triggers a programmatic change in dysfunctional myeloid-derived cells within mouse tumors. J Clin Investig. 2011;121:4746-57.

112. Kerkar SP, Leonardi AJ, van Panhuys N, Zhang L, Yu Z, Crompton JG, et al. Collapse of the tumor stroma is triggered by IL-12 induction of Fas. Mol Ther: J Am Soc Gene Ther. 2013;21:1369-77.

113. Pegram HJ, Lee JC, Hayman EG, Imperato GH, Tedder TF, Sadelain M, et al. Tumor-targeted T cells modified to secrete IL12 eradicate systemic tumors without need for prior conditioning. Blood. 2012;119:4133-41.

114. Xie YJ, Dougan M, Jailkhani N, Ingram J, Fang T, Kummer L, et al. Nanobody-based CAR $\mathrm{T}$ cells that target the tumor microenvironment inhibit the growth of solid tumors in immunocompetent mice. Proc Natl Acad Sci USA. 2019;116:7624-31.

115. Tanoue K, Rosewell Shaw A, Watanabe N, Porter C, Rana B, Gottschalk S, et al. Armed oncolytic adenovirusexpressing PD-L1 mini-body enhances antitumor effects of chimeric antigen receptor $t$ cells in solid tumors. Cancer Res. 2017;77:2040-51.

116. Suarez ER, Chang de K, Sun J, Sui J, Freeman GJ, Signoretti S, et al. Chimeric antigen receptor $\mathrm{T}$ cells secreting anti-PD-L1 antibodies more effectively regress renal cell carcinoma in a humanized mouse model. Oncotarget. 2016;7:34341-55.

117. Hartley J, Abken H. Chimeric antigen receptors designed to overcome transforming growth factor-beta-mediated repression in the adoptive T-cell therapy of solid tumors. Clin Transl Immunol. 2019;8:e1064.

118. Mezrich JD, Fechner JH, Zhang X, Johnson BP, Burlingham WJ, Bradfield CA. An interaction between kynurenine and the aryl hydrocarbon receptor can generate regulatory T cells. J Immunol. 2010;185:3190-8.

119. Wei P, Hu GH, Kang HY, Yao HB, Kou W, Liu H, et al. An aryl hydrocarbon receptor ligand acts on dendritic cells and $\mathrm{T}$ cells to suppress the Th17 response in allergic rhinitis patients. Lab Investig. 2014;94:528-35.

120. Ravishankar B, Liu H, Shinde R, Chaudhary K, Xiao W, Bradley $\mathrm{J}$, et al. The amino acid sensor GCN2 inhibits inflammatory responses to apoptotic cells promoting tolerance and suppressing systemic autoimmunity. Proc Natl Acad Sci USA. 2015;112: 10774-9.

121. Ninomiya S, Narala N, Huye L, Yagyu S, Savoldo B, Dotti G, et al. Tumor indoleamine 2, 3-dioxygenase (IDO) inhibits CD19CAR T cells and is downregulated by lymphodepleting drugs. Blood. 2015;125:3905-16.

122. Wang LC, Lo A, Scholler J, Sun J, Majumdar RS, Kapoor V, et al. Targeting fibroblast activation protein in tumor stroma with chimeric antigen receptor $\mathrm{T}$ cells can inhibit tumor growth and augment host immunity without severe toxicity. Cancer Immunol Res. 2014;2:154-66.

123. Zhang P, Zhao S, Wu C, Li J, Li Z, Wen C, et al. Effects of CSF1Rtargeted chimeric antigen receptor-modified NK92MI \& $\mathrm{T}$ cells on tumor-associated macrophages. Immunotherapy. 2018;10:935-49.

124. Cassetta L, Kitamura T. Macrophage targeting: opening new possibilities for cancer immunotherapy. Immunology. 2018;155:285-93.

125. Lim AR, Rathmell WK, Rathmell JC. The tumor microenvironment as a metabolic barrier to effector $\mathrm{T}$ cells and immunotherapy. eLife. 2020:5;9:e55185.

126. McKinney EF, Smith KGC. Metabolic exhaustion in infection, cancer and autoimmunity. Nat Immunol. 2018;19:213-21.

127. Cham CM, Driessens G, O'Keefe JP, Gajewski TF. Glucose deprivation inhibits multiple key gene expression events and effector functions in CD8+ T cells. Eur J Immunol. 2008;38:2438-50.

128. Shi LZ, Wang R, Huang G, Vogel P, Neale G, Green DR, et al. HIF1alpha-dependent glycolytic pathway orchestrates a metabolic checkpoint for the differentiation of TH17 and Treg cells. J Exp Med. 2011;208:1367-76.

129. Scharping NE, Menk AV, Moreci RS, Whetstone RD, Dadey $\mathrm{RE}$, Watkins $\mathrm{SC}$, et al. The tumor microenvironment represses $\mathrm{T}$ cell mitochondrial biogenesis to drive intratumoral $\mathrm{T}$ cell metabolic insufficiency and dysfunction. Immunity. 2016;45:374-88.

130. Leone RD, Powell JD. Metabolism of immune cells in cancer. Nat Rev Cancer. 2020:20:516-31.

131. Poorebrahim M, Sadeghi S, Fakhr E, Abazari MF, Poortahmasebi V, Kheirollahi A, et al. Production of CAR T-cells by GMPgrade lentiviral vectors: latest advances and future prospects. Crit Rev Clin Lab Sci. 2019;56:393-419.

132. Sacchetti B, Botticelli A, Pierelli L, Nuti M, Alimandi MJ. CAR$\mathrm{T}$ with license to kill solid tumors in search of a winning strategy. Int J Mol Sci. 2019;20:1903.

133. Zeng S, Shen WH, Liu L. Senescence and cancer. Cancer Transl Med. 2018;4:70-4.

134. Chen Z, Trotman LC, Shaffer D, Lin HK, Dotan ZA, Niki M, et al. Crucial role of p53-dependent cellular senescence in suppression of Pten-deficient tumorigenesis. Nature. 2005;436:725-30.

135. Yu S, Yi M, Qin S, Wu K. Next generation chimeric antigen receptor T cells: safety strategies to overcome toxicity. Mol Cancer. 2019;18:125.

136. Bonifant CL, Jackson HJ, Brentjens RJ, Curran KJ. Toxicity and management in CAR T-cell therapy. Mol Ther Oncolytics. 2016;3:16011. 